\title{
Digital power control circuit with pattern recognition for quartz metal
}

\section{halide discharge lamps}

\author{
Yuzhuo Pan ${ }^{1, a}$, Libin Huang ${ }^{1, b}$, Shengming Chen ${ }^{1, c}$ and Shanhe $S u^{2, d, ~ * ~}$ \\ ${ }^{1}$ College of Physics and Information Engineering, Quanzhou Normal University, Quanzhou 362000, \\ China \\ ${ }^{2}$ Beijing Computational Science Research Center, Beijing 100084, China \\ ayzpan@qztc.edu.cn, b278580146@qq.com , c1010520096@qq.com , dsushanhe@csrc.ac.cn
}

Keywords: Quartz metal halide discharge lamps; Digital control; Pattern recognition; Efficiency Abstract. An intelligent electrical circuit for controlling the operation of quartz metal halide discharge $(\mathrm{QMH})$ lamps is proposed. The lamp can be operated steadily at high-frequency by integrating the microcontroller ATmega128. With the application of pattern recognition, the control system enables the lamp to be turned on and off automatically according to the environment condition and maintain high-performance constant power. The results show that the efficiency of the driving circuit can approach $94.3 \%$. The proposed model will provide opportunities to design reliable and cost-effective QMH lamps.

\section{Introduction}

Quartz metal halide discharge (QMH) lamps, as a type of high intensity discharge lamp, are typically used in public lightings [1,2]. QMH lamps powered by traditional inductive ballast driving circuits have disadvantages of high energy consumption and low power factors [3]. There are numerous researches making efforts to design digital ballast to replace its inductive counterpart $[4,5]$.

Another problem of QMH lamps is that most lamps can not be controlled automatically. Manual control may give rise to unavoidable inconveniences, because manual intervention is required and the lack of management skills can result in energy waste. In addition, an instant extinguish of the number of lamps at midnight may cause human eye discomfort and the occurrence of various accidents.

Here, we will build a digital driving circuit to combine intelligent control technologies with QMH lamps. The rest of the paper is organized as follows: First, we describe the circuit structure in detail. Next, the strategy, which allow the lamp to be controlled automatically, will be presented. At last, the performance of the lighting system will be determined via laboratory experiments.

\section{Circuit structure}

The circuit structure of the QMH lamp is composed of a driving circuit, a microcontroller circuit ATmega128, an auxiliary power supply module, and a LCD5110 display module. The driving circuit consists of an EMI filter circuit, an active power factor correction (APFC) system, a half-bridge driving circuit, an igniter, and a protection circuit, as shown in Fig. 1. The micro control circuit comprises a light collection circuit, a touch key control circuit, a real-time detection circuit, a brownout detection circuit, a hot start and high temperature protection circuit, a D/A converter 
circuit, and a switching circuit. The auxiliary power supply module is composed of VIPER22A using the flyback configuration with the output voltage control.

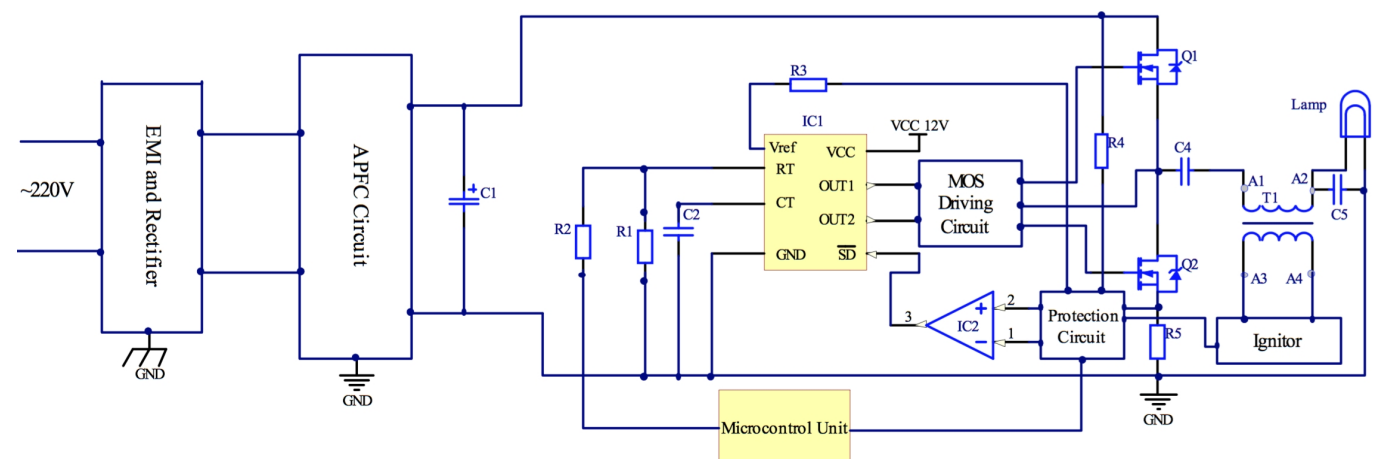

Figure 1. Configuration of the QMH driving circuit.

The schematic diagram of the half-bridge driving circuit is also shown in Fig. 1. The MOS switches Q1 and Q2 are turned on and off by SG3525. For the safety of the operation, the current $I_{i}$ and the bus voltage $U_{b u s}$ of the MOS switches are detected. The information is transferred to the microcontroller for recognition. When the system is working in the abnormal condition, the microcontroller will offer feedback to increase the voltage of the shutdown terminal of SG3525 for protecting the half-bridge driving circuit. The half-bridge driving circuit shows competitive advantages of simple struction and easy operation [6, 7]. Generally, the operating voltage of QMH lamps is about $106 \mathrm{~V}$ and the bus voltage $U_{\text {bus }}$ is around $400 \mathrm{~V}$.

For a QMH lamp operating at high frequencies, the lamp can be regarded as a load with a constant resistance $R_{\text {Lamp. }}$. Under the steady state condition, the power output of the lamp is equal to

$$
P_{\text {Lamp }}=\frac{2 U_{b u s}^{2} R_{\text {Lamp }}}{\pi^{2}\left[\left(\omega L-\frac{1}{\omega C_{s}}\right)^{2}+R_{\text {Lamp }}^{2}\right]},
$$

where $L$ is the inductance, $C_{s}$ is the capacitance and $\omega$ is the driven resonance frequency of the series RLC resonant circuit shown in Fig. 1.

The power output of the lamp is given by

$$
P_{\text {Lamp }}=U_{\text {bus }} I_{i} \text {. }
$$

\section{Digital control strategies}

ATmega128 is a high-performance, low-power CMOS 8-bit microcontroller. In this section, we will provide digital control strategies on how to switch the lamp on and off automatically according to the environment. Figure 2 displays the flowchart of a QMH lamp in the normal working condition (a) and the flowchart of the gradient dimming (b). 
a

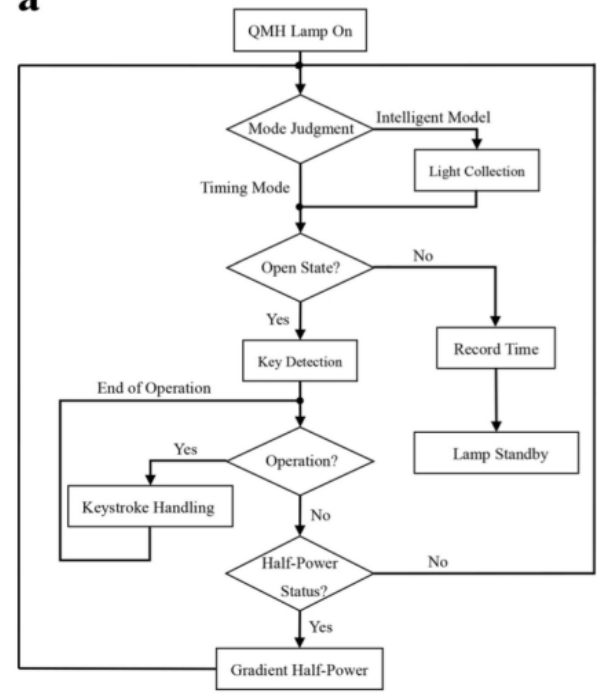

b

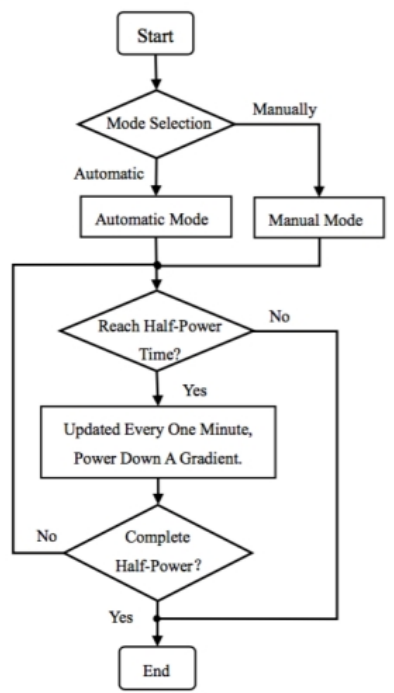

Figure 2. (a) The flowchart of a QMH lamp in the normal working condition. (b) The flowchart of the gradient dimming.

As shown in Fig.2, when the lamp is turned off, the microcontroller will record the time and the system will enter the standby state. When the lamp is operating well, the system will manipulate key detection. If the key input exists, the system will work properly until the half-power state being satisfied. The gradient dimming is another important point in this article. The time for the gradient dimming can be adjusted flexibly using the automatic mode or the manual mode. The time for the half-power control can be modified according to the ambient detected by the light sensor. As a result, the instant extinguish of the number of lamps at midnight, which may cause human eye discomfort or the occurrence of various accidents, is no more necessary.

\section{Experimental results}

In the experiment, a 250W QMH lamp (JLZ250W, OSRAM) is used. The standard input AC voltage is $220 \mathrm{~V}$. The voltage and the current are measured by DM3058E $5 \frac{1}{2}$ Digit Digital Multimeter. All waveforms are recorded by the digital phosphor oscilloscope (Tektronix DPO2014B with 100-200MHz bandwidth). The IT9121 digital power meter with $100 \mathrm{kHz}$ bandwidth is used to measure the power input and the power factor. The power output of the lamp is obtained by using Yokogawa WT210 Digital Power Meter with 100kHz bandwidth.

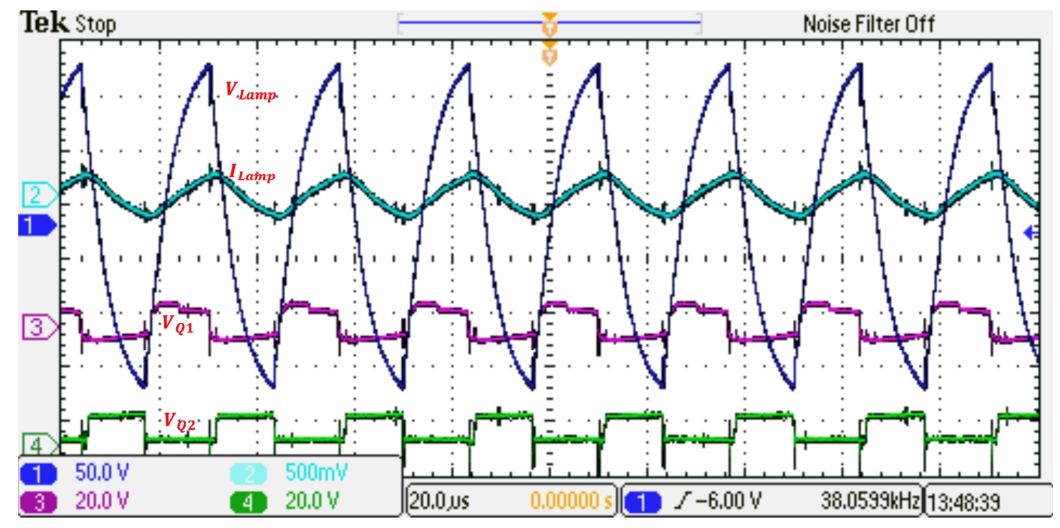

Figure 3. The lamp voltage $V_{\text {Lamp }}(\mathrm{CH} 1)$, the lamp current $I_{\text {Lamp }}(\mathrm{CH} 2)$, and the driving signals for MOS switches $V_{Q 1}(\mathrm{CH} 3)$ and $V_{Q 2}(\mathrm{CH} 4)$,. 
Figure 3 displays the lamp voltage $V_{\text {Lamp }}(\mathrm{CH} 1)$, the lamp current $I_{\text {Lamp }}(\mathrm{CH} 2)$, and the waveforms of driving signals for MOS switches $V_{Q 1}(\mathrm{CH} 3)$ and $V_{Q 2}(\mathrm{CH} 4)$. The high order harmonic distortion does not appear in the circuit. The waveforms of the lamp voltage $V_{\text {Lamp }}$ and the lamp current $I_{\text {Lamp }}$ bear the same frequency and phase.
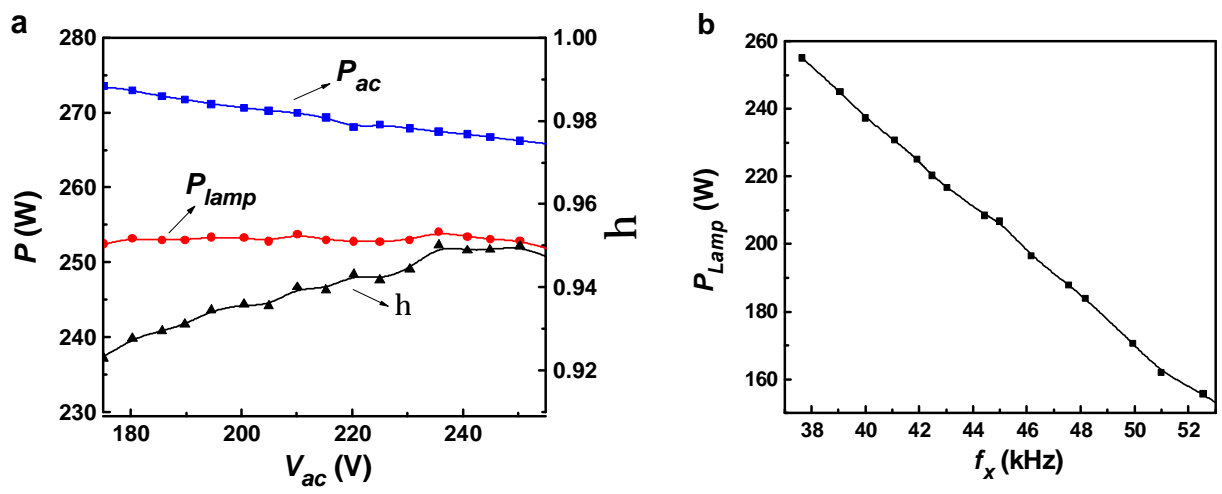

Figure 4. (a) Curves of the AC power input $P_{a c}$, the power output $P_{\text {Lamp }}$, and the electrical efficiency $\eta$ varying with the input voltage $V_{a c}$, where the frequency of the PWM control circuit $f_{x}$ is around $37.89 \mathrm{kHz}$. (b) The curve of the power output $P_{\text {Lamp }}$ varying with the switching frequency $f_{x}$.

The power output $P_{\text {Lamp }}$ of the lamp as a function of the AC input voltage $V_{a c}$ is displayed in Fig.4 (a). As $V_{a c}$ decreases from $255 \mathrm{~V}$ to $175 \mathrm{~V}$, the power output $P_{\text {Lamp }}$ is stable near $250 \mathrm{~W}$. The lamp can be operated in a steady state. Figure 4(a) also presents the curves of the AC power input $P_{a c}$ and the electrical efficiency $\eta$ varying with $V_{a c}$. The AC power input $P_{a c}$ decreases as $V_{a c}$ increases. When $V_{a c}$ is small, the amount of energy wasted by the driving circuit will be enlarged, leading to the decrease of $\eta$. From the efficiency curve, it can be seen that $\eta$ stays between $92.2 \%$ and $95.1 \%$. It can be larger than $94.3 \%$ when $V_{a c}$ is $220 \mathrm{~V}$.

Figure 4(b) shows the curve of the power output of the lamp $P_{\text {Lamp }}$ varying with the frequency of the PWM control circuit $f_{x}$. $P_{\text {Lamp }}$ monotonically decreases with the increase of $f_{x}$. When $f_{x}$ increases from $37.7 \mathrm{kHz}$ to $53.8 \mathrm{kHz}, P_{\text {Lamp }}$ decreases from $255.1 \mathrm{~W}$ to $149.1 \mathrm{~W}$. It means that the present design of digital control circuit is convenient and flexible for half-power control and gradient dimming. The microcontroller can detect the current, the voltage, and the frequency of the lamp for the purposes of searching a stable power point by the successive-approximation method.

\section{Conclusions}

By replacing the analog circuit with the digital control circuit, we are capable of realizing various digital control strategies and stable operation in QMH lamps. Based on the method of successive-approximation, the microcontroller can adjust the power point to obtain the load matching between the driving circuit and the lamp. Experimental results show that the circuit efficiency can be greater than $94.3 \%$, which will offer great promise in terms of improving the device performance.

\section{Acknowledgments}

This work has been supported by Key Project of Science and Technology Department of Fujian Province (No. 2016H0030), Practice and Internship Base for College Students of Fujian Province (No. S2013011), Key Discipline of Electronic Science and Technology, and Postdoctoral Science Foundation of China (No. 2015M580964), People's Republic of China. 


\section{References}

[1] M. Radecker, F. Dawson, Ballast-on-a-chip: Realistic expectation or technical delusion? IEEE Ind. Appl. Mag., 10, (2004), 48-58.

[2] A. Toumi, L. Chhun, S. Bhosle, G. Zissis, P. Maussion, B. Baumann, M. Wolff, Acoustic resonance characterization and numerical model including acoustic streaming in an HID lamp, IEEE Trans. Ind.Appl., 49, (2013), 1954-1960.

[3]J. Garcia, A. J. Calleja, D. G. Vaquero, J. Ribas, E. L. Corominas, Single-switch offline ballast with PFC for low-wattage metal halide lamps, IEEE Trans. Ind. Appl., 46, (2010), 2212-1220.

[4] C. Branas, F. Azcondo, R. Zane, Power-mode control of multiphase resonant electronic ballast, IEEE Trans. Ind. Electron. 59, (2012), 1770-1778.

[5] J. C. Álvarez Antón, C. Blanco, F. J. Ferrero, J. C. Viera, N. Bordel, An acoustic resonance band detection workbench for HID lamps, IEEE Trans. Ind. Appl., 43, (2007), 1191-1197.

[6] D. H. J. van Casteren, M. A. M. Hendrix, J. L. Duarte, Transition mode stacked buck converter for HID lamps, IEEE Trans. Ind.Appl., 44, (2008), 68-72.

[7] R. O. Sanchez, N. Vazquez, C. Hernandez, E. Rodriguez, S. Pinto, M. Juarez, Electric dynamic modeling of HID lamps for electronic ballast design, IEEE Trans. Ind. Electron., 57, (2010), $1655-1662$. 